\title{
The Green Synthesis of Nanoparticle Zinc Oxide (ZnO) Using Aloe Vera Leaf Extract: Structural and Optical Characterization Reviews
}

\author{
Mohd Fadhlan Shah Hermandy ${ }^{1}$, Mohd Zaki Mohd Yusoff ${ }^{2}$, Muhammad Syarifuddin Yahya ${ }^{3}$, \\ Md Rabiul Awal ${ }^{4}$ \\ ${ }^{1}$ Faculty of Chemical Engineering, Universiti Teknologi MARA Cawangan Pulau Pinang, 13500, Permatang \\ Pauh, Pulau Pinang, Malaysia, fadhlan.shah@gmail.com \\ ${ }^{2}$ Department of Applied Sciences, Universiti Teknologi MARA Cawangan Pulau Pinang, 13500, Permatang \\ Pauh, Pulau Pinang, Malaysia, mzmy83@gmail.com \\ ${ }^{3}$ Faculty of Ocean Engineering Technology and Informatics, Universiti Malaysia Terengganu, 21030 Kuala \\ Nerus, Terengganu, Malaysia, syarif_yahya@umt.edu.my \\ ${ }^{4}$ Department of Electronics \& Instrumentation, Faculty of Ocean Engineering Technology and Informatics, \\ Universiti Malaysia Terengganu, 21030 Kuala Nerus, Terengganu, Malaysia, rabiulawal1@gmail.com
}

\section{ABSTRACT}

This work is to review the previous, current and latest findings on the structural and optical properties of the $\mathrm{ZnO}$ nanoparticles formed by the various green synthesis methods. Each method involves a different chemical reaction, and it affects the quality of the $\mathrm{ZnO}$ formed on the substrates. Zinc oxide $(\mathrm{ZnO})$ is a wide and direct semiconductor with a wurtzite crystal structure. Nano-scaled $\mathrm{ZnO}$ as today has been synthesized through green synthesis using natural plant extract as an effective 'reducing agent' of the metal precursor, which has been reported to be an effective cleaner and environment-friendly alternative towards the physical and chemical methods. This Final Year Report is based on the green synthesis and the main physical optical properties of pure $\mathrm{ZnO}$ nanoparticles synthesized by a completely green chemistry process using the natural extract of Aloe Barbadensis Miller (Aloe Vera) Leaf Extract to bio-reduce the zinc precursor. The different zinc precursor concentration is recognized to affect the particle size as well as on the optical properties such as surface morphology, porosity, particle size and the polymeric properties of $\mathrm{ZnO}$ nanoparticles. The green synthesis of NPs $\mathrm{ZnO}$ use is much better and affordable because the process provides more eco-friendly, economical, free toxic, and easy to compose rather than the chemical and physical methods. The main characteristics and the applications of these synthesized zinc oxide are also reported by using different analysis equipment to be the main focus on such as X-Ray Diffraction (XRD) Analysis, Field Emission Scanning Electron Microscopy (FE-SEM), Fourier Transform Raman (FT-Raman), Photoluminescence Spectra (PL)
Key words : Zinc Oxide, Aloe Vera, Green Synthesis, ZnO.

\section{INTRODUCTION}

Zinc Oxide $(\mathrm{ZnO})$ is a distinctive compound due to its unmatched optical and electrical properties where it is acknowledged for its non-toxic inorganic metal [1], unparalleled optical and electrical properties [2], plus with the multifunctional with many application in the different field [3]. $\mathrm{ZnO}$ has a variety of applications such as in piezoelectric devices, chemical sensors, environmental protection, optoelectronics, pharmaceutical and cosmetic industries [4] [5]. Moreover, $\mathrm{ZnO}$ also has photocatalytic properties [6] with its application in the food and agriculture industry [7]. Each of the properties and its application can be modified by changing the size and morphology [8]. Other than that, $\mathrm{ZnO}$ Nanoparticles (NPs) also have broad applications in biological and medical such as healing nanomedicine [9], and cosmetic industries due to its antioxidant, antimicrobial, and antibacterial activity [10]-[12].

There are different methods in synthesizing nanoparticles for examples the physical, chemical and green methods [13]. Nowadays, green synthesis methods which are highly safe, environmentally friendly, cost-effective and rapid are highly recommended because of its advantages in comparison towards the chemical and physical methods [14], [15]. In this green synthesis method, plants, alga, microorganisms and even enzymes are used in synthesizing. In addition, by using the different NPs properties, the shape and size can be controlled [16].

Plant parts such as root, stem, leaf, fruits and even seed can be used for $\mathrm{ZnO}$ Nanoparticles synthesis [17], [18]. The plant extract used to green synthesis the $\mathrm{ZnO} \mathrm{Nps}$ is a more widely 
used process. The plant extract collected contains secondary metabolites [19]. Other than that, it also contains some phytochemical compound as stabilizing, phytochemical compound and capping agents for the synthesis of $\mathrm{ZnO} \mathrm{Nps}$ [20], [21].

Aloe Barbadensis Miller (Aloe Vera) leaves have countless beneficial properties which many researchers discovered it can be a benefit in many fields especially in medicinal, agricultural, cosmetics etc. [22], [23]. On top of that, a high amount of phenolic compound is also found in Aloe Vera, which are important in cancer treatment nowadays [24]. All part of the Aloe Vera plant such as leaves, roots and stem have been used in agriculture cosmetics and medicinal because of the plant's properties. Properties such as the increasing of effectiveness in antibiotics, the antifungal properties in agriculture and also inhibiting cancer cells [25], [26]. Hence, the extraction of the properties in a safe way by green synthesis the $\mathrm{ZnO}$ NPs is crucial.

Zinc acetate dihydrate $\left(\mathrm{Zn}\left(\mathrm{CH}_{3} \mathrm{COO}\right)_{2} \cdot 2 \mathrm{H}_{2} \mathrm{O}\right)$ affects the optical properties of $\mathrm{ZnO}$ Nps. The fast nucleation during the synthesis process may cause the inverse relationship between the optical properties of $\mathrm{ZnO}$ nanoparticles and zinc acetate dihydrate concentration [27]. To analyse the optical characterization, a few methods were completed to confirm the properties of the $\mathrm{ZnO}$ Nps. The methods used were XRD analysis where the structure of hexagonal wurtzite of $\mathrm{ZnO}$ NPs can be observed [28], Field Emission Scanning Electron Microscopy (FE-SEM) analysis to determine the surface morphology, porosity, particle size of the ZnO NPs [29] and Fourier Transform Infrared (FTIR) Spectroscopy Analysis is to determine the polymeric properties of $\mathrm{ZnO}$ NPs by relying on infrared light to scan samples and observe bond properties [30]. Besides that, the Ultraviolet-visible spectroscopy (UV-vis) is used to determine the concentration of an analyte in a solution [31].

Due to the high demands of environmental-friendly nanoparticles, high cost and harmful consequences of the commercial method of nanoparticles technology, green synthesis of nanoparticles were recently and widely research. However, through the green synthesis of the $\mathrm{ZnO}$ NPs, the concentration of Zinc acetate dihydrate affected the optical characterization of the NPs. Previous research demonstrates that the nanostructure's size is corresponding to the precursor [32], $\left(\mathrm{Zn}\left(\mathrm{CH}_{3} \mathrm{COO}\right)_{2} \cdot 2 \mathrm{H}_{2} \mathrm{O}\right)$ concentration. Controlled concentration could be obtained by the different characteristics of $\mathrm{ZnO}$ and with the different characteristics of the $\mathrm{ZnO}$ NPs which applies in the different fields on the usage of $\mathrm{ZnO}$ NPs.

\section{REVIEW}

\subsection{Green Synthesis}

Green synthesis or biosynthesis is one of the three methods of synthesizing metal nanoparticles which are physical synthesis, chemical synthesis and biosynthesis. In comparing with the physical and chemical synthesis, aside from the toxic nature of the method, the method also produced various disadvantages such as distorted structure, limited growth and slow production rate of the synthesized nanoparticles [33]. Biosynthesis is safer, cost-saving and environmentally friendly.

In obtaining the desired nanoparticles, the two separate basic principles of synthesis are the top-down and bottom-up approaches [13]. Usually, in using these commercial methods, physical and chemical techniques are used in producing the nanoparticles. However, physical techniques are considered highly expensive, while the chemical techniques are considered harmful to the environment and living organisms. Figure 1 shows the different synthesis approaches available for the preparation of metal nanoparticles. Figure 2 shows the example synthesis route of $\mathrm{ZnO}$ nanostructures from the leaf extracts.

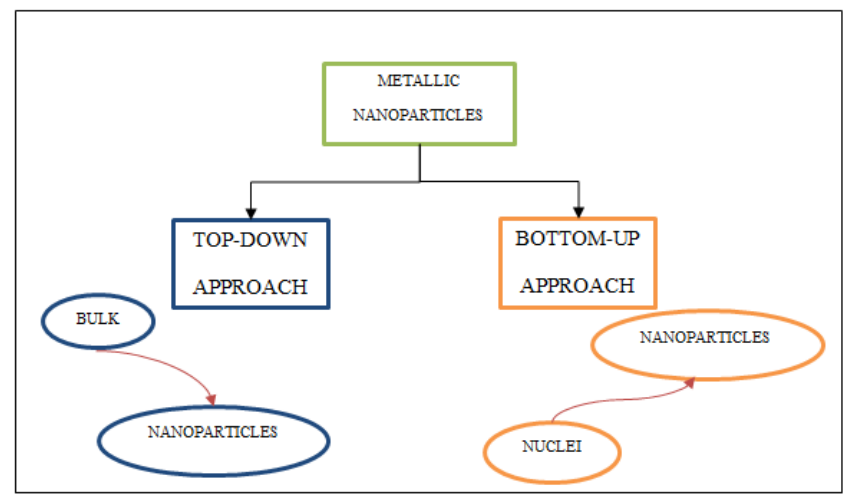

Figure 1: Possible synthesis methods for metal nanoparticles preparation [13]

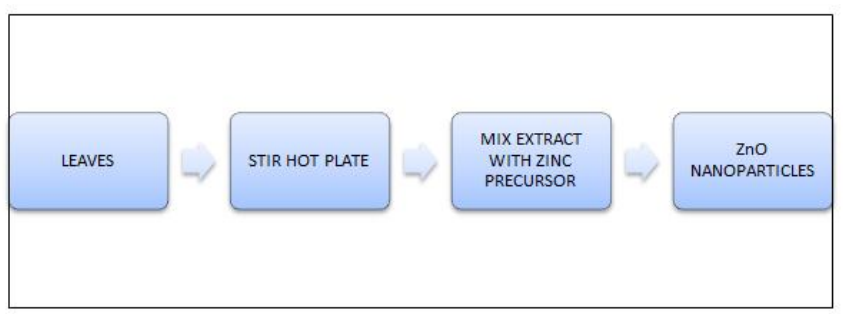

Figure 2: Example workflow of the $\mathrm{ZnO}$ nanostructures synthesis method from leaf extracts [34].

\subsection{Zinc Oxide}

Crude zinc oxide is a yellow-grey granular solid with no odour. It is insoluble in water. Table 1 shows the general properties of $\mathrm{ZnO}$.

Table 1: Properties of $\mathrm{ZnO}$ [36]

\begin{tabular}{|l|l|}
\hline \multicolumn{2}{|c|}{ Properties of $\mathrm{ZnO}$} \\
\hline Chemical Structure & $\mathrm{ZnO}$ \\
\hline Molecular Weight & $81.389 \mathrm{~g} / \mathrm{mol}$ \\
\hline Appearance & White solid \\
\hline Odour & Odourless \\
\hline Crystal Structure & Wurtzite \\
\hline Coordination Geometry & Tetrahedral \\
\hline Band Gap & $3.37 \mathrm{eV}$ \\
\hline Density & $5.606 \mathrm{~g} / \mathrm{cm} 3$ \\
\hline
\end{tabular}

Zinc Oxide is considered a primary hazard and danger to the environment. To restrict its spread to the community, urgent measures should be taken. Metal fume fever with symptoms of 
chills, fever, muscle pain, nausea and vomiting can result in prolonged dust inhalation [35]. Hence proper personal protection equipment is required to prevent any unwanted incident from occurring.

\subsection{Zinc Oxide Nanostructure}

Zinc Oxide is known for its crystalline structure. Wurtzite, Zinc blende and rocksalt are the three crystalline structures of the $\mathrm{ZnO}$ [37]. The structure of rocksalt exists during high-pressure condition while the structure of zinc blende would be formed when the $\mathrm{ZnO}$ growth on the substrate and the structure in a proper cubic lattice. Wurtzite structure is in hexagonal close-packed, which consist of zinc $(\mathrm{Zn})$ and oxygen $(\mathrm{O})$ atom with attached at tetrahedral sites in alternate arrangement [38].

\subsection{Application of Zinc Oxide}

In the semiconducting and piezoelectric properties, $\mathrm{ZnO}$ has a variety of applications such as in the piezoelectric devices, chemical sensors, environmental protection, optoelectronics, pharmaceutical, cosmetic industries and even textile with its coating technology [5],[4]. Moreover, $\mathrm{ZnO}$ also has photocatalytic properties with its application in food as in food packaging and agriculture industry for its antifungal properties [6],[7]. All the properties and its application can be modified by changing the size and morphology [8]. In addition, $\mathrm{ZnO}$ Nanoparticles (NPs) also have wide applications in biological and medical such as healing nanomedicine [9], and cosmetic industries due to its antioxidant, antimicrobial, and antibacterial activity [10]-[12].

\subsection{Aloe Vera}

Aloe Vera is a juicy plant species in the family of Aloe. The plant, which is an evergreen perennial is originating from the Arabian Peninsula which also can be found in hot, semi-tropical and arid climates throughout the world. It is cultivated for agricultural and medicinal uses [39]. All parts of the plant can be used in various ways of application which makes the plant a multifunctional plant [22], [40]. Particularly in medicinal nowadays, Aloe Vera gives the benefits in treating health problem from aiding small wounds to treating cancer cell [23], [39].

\section{STRUCTURAL AND OPTICAL CHARACTERIZATION REVIEWS}

\subsection{Structural Review of Zinc Oxide Synthesis with Aloe Vera}

This topic is about the morphology of the surface, the structural and optical characterization of zinc oxide nanoparticles using an extract from the banana leaves. For this study, the characterizations are important in achieving high-quality zinc oxide nanoparticles through the usage of plant extraction. A few devices are needed to identify and investigate nanoparticles with zinc oxide, such as scanning electron microscopy (SEM), XRD, FT-Raman Spectroscopy, UV-Vis, FTIR, and Photoluminescence (PL) Spectroscopy as per in the previous study. Table 2 shows the biosynthesis analysis of zinc oxide nanoparticles using an extract from aloe vera leaves.

The optical characteristics of $\mathrm{ZnO}$ were determined by using SEM, XRD, Raman Spectroscopy and Photoluminescence. Parameters like the $\mathrm{pH}$, temperature of the mixture and the concentration of the zinc precursors, were compared through literature review. In addition, the equipment used to determine a process that scans a sample with an electron beam to produce a magnified image was by SEM [40]. Meanwhile, XRD was primarily used for crystalline materials' phase identification as well as obtaining information on unit cell dimensions [40]. As for the technique which provides detailed information about chemical structure, phase and polymorphy, crystallinity and molecular interactions Raman spectroscopy was used, and it is also used to stimulate the emission of a photon from any matter by Photoluminescence [11].

Table 2: Reviewed Aloe Vera Literature

\begin{tabular}{|l|l|l|}
\hline No. & Authors / Years & $\begin{array}{l}\text { Optical And Structural } \\
\text { Findings }\end{array}$ \\
\hline 1 & $\begin{array}{l}\text { E. Varghese and M. } \\
\text { George, 2015 [40] }\end{array}$ & $\begin{array}{l}\text { The key advantage of this } \\
\text { synthesis is, the synthetic } \\
\text { path, cost-effective and } \\
\text { straightforward. Thus, we } \\
\text { can extract the aloe vera leaf } \\
\text { for large-scale ZnONP } \\
\text { growth. The synthesized } \\
\text { nanoparticles are very active } \\
\text { in the degradation in the } \\
\text { zinc precursor solution, and } \\
\text { in the presence of visible } \\
\text { light, illumination catalyzes } \\
\text { the decolonisation. }\end{array}$ \\
\hline 2 & $\begin{array}{l}\text { R. Majumder et al, } \\
\text { Thtructure of the surface } \\
\text { morphology is obtained in } \\
\text { irregular shapes and } \\
\text { confirms the existing } \\
\text { ZnONPs by the strongest } \\
\text { single bond detected, which } \\
\text { is oxygen and hydrogen } \\
\text { bond. }\end{array}$ \\
\hline 3 & G. Parthasarathy et al, & $\begin{array}{l}\text { Aloe vera leaves contain } \\
\text { alkaloids, tannins, } \\
\text { flavonoids, carbohydrates, } \\
\text { and terpenoids while the } \\
\text { neem plant contains } \\
\text { alkaloids, steroids, } \\
\text { flavonoids, carbohydrates, } \\
\text { glycosides, and terpenoids. } \\
\text { Such compounds may }\end{array}$ \\
\hline
\end{tabular}




\begin{tabular}{|c|c|c|}
\hline & & $\begin{array}{l}\text { account for their medicinal } \\
\text { uses }\end{array}$ \\
\hline 4 & K. Ali et al, 2016 [43] & $\begin{array}{l}\text { Green synthesis is a safer } \\
\text { option that avoids the use of } \\
\text { high temperature, strain, } \\
\text { energy and harmful } \\
\text { chemicals without the need } \\
\text { for extrinsic surfactants or } \\
\text { capping agents in the } \\
\text { synthesis of metal NPs. }\end{array}$ \\
\hline 5 & $\begin{array}{l}\text { T. K. Mendy et al, } 2019 \\
\text { [27] }\end{array}$ & $\begin{array}{l}\text { Green synthesis made using } \\
\text { Aloe vera extract with zinc } \\
\text { precursor and zinc oxide can } \\
\text { be produced with a specific } \\
\text { ratio between plant extract } \\
\text { and metal ion and the } \\
\text { observation on the colour } \\
\text { change has corroborated } \\
\text { formation of nanoparticles. }\end{array}$ \\
\hline 6 & $\begin{array}{l}\text { C. E. Farrugia et al, } \\
2019 \text { [22] }\end{array}$ & $\begin{array}{l}\text { In ALE-ZnONP formation, } \\
\text { the study on ALE-ZnONPs } \\
\text { revealed the compounds } \\
\text { preponderance such as } \\
\text { pentadecanoic acid and } \\
\text { tetra-conate in ALE. In } \\
\text { addition to proteins and } \\
\text { other auxiliary } \\
\text { phytochemicals, the } \\
\text { elements or compounds may } \\
\text { be accountable for bestowing } \\
\text { stability to associated } \\
\text { ZnONPs. The specificity of } \\
\text { phytochemicals as } \\
\text { presumptive stabilisers and } \\
\text { capping agents is } \\
\text { speculative. }\end{array}$ \\
\hline 7 & $\begin{array}{l}\text { B. H. Abbasi et al, } 2019 \\
\text { [42] }\end{array}$ & $\begin{array}{l}\text { This study indicates that, } \\
\text { given their source, these } \\
\text { substrates serve as reducers } \\
\text { and stabilizers or as } \\
\text { chelating substances. It is } \\
\text { important to note that } \\
\text { parameters such as } \\
\text { temperature conditions, } \\
\text { reaction time, pH and } \\
\text { concentrations, in addition } \\
\text { to the disparity between the } \\
\text { compositions found in } \\
\text { biological extracts, greatly } \\
\text { alter the final properties of } \\
\text { the synthesized } \\
\text { nanoparticles. }\end{array}$ \\
\hline 8 & $\begin{array}{l}\text { G. Canche-Escamilla } \\
\text { et al, } 2019 \text { [24] }\end{array}$ & $\begin{array}{l}\text { The concentrations of both } \\
\text { the biological extract and the } \\
\text { source of zinc, as well as the } \\
\text { pH of the solution, play an } \\
\text { significant role in the final }\end{array}$ \\
\hline
\end{tabular}

\begin{tabular}{|c|c|c|}
\hline & & $\begin{array}{l}\text { properties of } \mathrm{ZnONPs} \\
\text { obtained by a green path. }\end{array}$ \\
\hline 9 & C. Peng et al, 2019 [23] & $\begin{array}{l}\text { Due to its bio-compatibility } \\
\text { nature and efficient } \\
\text { synthesis protocols, ZnO } \\
\text { NPs were selected for the } \\
\text { current analysis. } \\
\text { Throughout the current } \\
\text { analysis, all the NPs } \\
\text { synthesized demonstrated } \\
\text { potent biological activities. } \\
\text { S-ZNPs have proved to be } \\
\text { the most potent antibacterial } \\
\text { agent against the bacterial } \\
\text { species being studied. It was } \\
\text { also found that S-ZNPs } \\
\text { possess the most potent } \\
\text { antioxidant capacity. }\end{array}$ \\
\hline
\end{tabular}

\subsubsection{The Effect of pH on Zinc Oxide Structure}

A systematic study of $\mathrm{ZnO}$ nanostructure morphological variation by fluctuating the $\mathrm{pH}$ of the precursor solution through the green solution process was presented in this review. $\mathrm{ZnO}$ nanorod morphology differs markedly from sheetlike to rod-like zinc oxide structure. Due to the diffraction patterns at all $\mathrm{pH}$ levels had been well correlated with regular $\mathrm{ZnO}$ [27]. High-resolution transmission electron microscopy (HR-TEM) and selected area electron diffraction pattern have confirmed crystallinity and nanostructures, indicating that the structure has evolved along with an ideal lattice fringe [24]. It is deduced that the size or morphology structure can be configured by the differences in $\mathrm{pH}$. In this context, lower $\mathrm{pH}$ is best suited for $2 \mathrm{D}$ structure, whereby the rod-like structure is developed from the higher $\mathrm{pH}$ values. In this context, the consistency of the substance is not affected by the $\mathrm{pH}$ solution as observed from the XRD pattern and FTIR spectroscopy significantly. Besides that, the optical properties (UV-vis spectroscopy) of the grown samples were also shown to have good optic properties compared to the bulk $\mathrm{ZnO}$ under different conditions.

\subsubsection{The Effect of Temperature on Zinc Oxide Structure}

At higher temperatures, due to agglomeration, the size of the zinc oxide nanoparticles increases. Raman spectra bands at extend explicitly indicate that the solution contains zinc oxide upon making the high peaks annealed while the FTIR converted radiation to zinc oxide. Also, the amount of zinc precursors being converted to zinc oxide depends on the temperature of the annealing process [39]. Optical transmittance data were used to determine the optical properties of the $\mathrm{ZnO}$ nanoparticles. As for the commodity optical band, temperature PL spectrum displays a strong UV band. Optical transmittance data were used to determine the optical properties of the $\mathrm{ZnO}$ nanoparticles. The crystalline consistency also can be improved by heat treatment of the 
crystals in an $\mathrm{O} 2$ atmosphere due to the effects of oxygen entering the crystal lattice, whereby there was an increasing in the stoichiometric proportion of the sample and reducing the vacancies of oxygen in $\mathrm{ZnO}$. For commodity optical band, temperature PL spectrum displays a strong UV band [23].

\subsubsection{The Effect of Precursor Concentration on Zinc Oxide Structure}

The concentration of the precursor effect on the structural, morphological and optoelectrical characteristics was investigated. XRD characterizations show that the samples are poly-crystalline with a preferential orientation. SEM analyzes however reveal that film morphology depends significantly on the concentration of the precursor including the outlining mechanisms governed by nucleation and/or growth. Based on the next layer built to be deposited in a stacked structure, it has been shown that roughness increases with an increasing precursor concentration while wet capacity can be adjusted by adjusting the precursor concentrations [38]. The present optical transmittance spectrum curves of $\mathrm{ZnO}$ films with different concentrations of precursors suggest that the films are highly transparent in the visible field. The opto-electrical analyzes in the studies also show that films that demonstrate higher electrical conductivity also have better photosensitive properties compared to the concentration variations [43]. In the future work, the application of $\mathrm{ZnO}$ as a photodetector in fiber optic [44] and $\mathrm{X}$-ray shielding [45] applications will be reviewed.

\section{CONCLUSION}

As a conclusion, numerous studies note that the possibility of using a green synthesis to obtain $\mathrm{ZnONPs}$ by using aloe vera is achievable. Besides that, the studies cited here suggest that with the given source, these substrates act as the reducing and stabilizing substances, or as chelating substances. It is interesting to note that parameters such as temperature conditions, reaction time, $\mathrm{pH}$, and concentrations, in addition to the difference between the discovered compositions in biological extracts, significantly alter the final properties of the synthesized nanoparticles. Between these parameters, the concentrations of both biological extract and zinc source and also the $\mathrm{pH}$, temperature of mixture and concentration of zinc precursor play a major role in the final properties of $\mathrm{ZnONPs}$ obtained using the green path, according to the cited literature. Although the complexity of biological substrates still poses a challenge to evaluate the green synthesis of nanoparticles, further investigations on the mechanism of formation of the biological synthesis of ZnONPs are necessary to achieve a better understanding of the chemical processes and reactions that occur during the synthesis. It seems that the green synthesis process, which is important for the large-scale production of ZnONPs, will be regulated and optimized with the designation of the described mechanism. Therefore, the rapidly advancing understanding of green synthesis outlined herein indicates that ZnONPs' enormous potential towards the industrial production in the near future using biological extracts.

\section{ACKNOWLEDGMENT}

The authors would like to express gratitude for the support given by the Universiti Malaysia Terengganu.

\section{REFERENCES}

1. E. He, H. Qiu, X. Huang, C. A. M. Van Gestel, And R. Qiu. Different Dynamic Accumulation and Toxicity of Zno Nanoparticles And Ionic Zn In The Soil Sentinel Organism Enchytraeus Crypticus, Environ. Pollut., pp. 510-518, Feb. 2019.

2. S. G. Kumar And K. S. R. K. Rao. Comparison of Modification Strategies Towards Enhanced Charge Carrier Separation And Photocatalytic Degradation Activity Of Metal Oxide Semiconductors (Tio 2 , Wo 3 And Zno). Appl. Surf. Sci., Vol. 391, pp. 124-148, Jan. 2017.

3. S. Kumar, D. Panigrahi, And A. Dhar. Efficiency Enhancement of Zno Based Inverted Bhj Solar Cells Via Interface Engineering Using C 70 Modifier, Org. Electron., Vol. 38, pp. 1-7, Nov. 2016.

4. D. Ponnamma, J.J. Cabibihan, M. Rajan, S.S. Pethaiah, K. Deshmukh, J.P. Gogoi, S.K. Pasha, M.B. Ahamed, J. Krishnegowda, B.N. Chandrashekar, and A.R. Polu. Synthesis, Optimization and Applications of Zno/Polymer Nanocomposites, Materials Science And Engineering C, Vol. 98. Elsevier Ltd, pp. 1210-1240, 01-May-2019.

5. S. Fan, Y. Liang, J. Xie, And Y. Hu. Exact Solutions To The Electromechanical Quantities Inside A Statically-Bent Circular Zno Nanowire By Taking Into Account Both The Piezoelectric Property And The Semiconducting Performance: Part I-Linearized Analysis, Nano Energy, Vol. 40, pp. 82-87, Oct. 2017.

6. M. Zare, K. Namratha, M. S. Thakur, S. Yallappa, And K. Byrappa. Comprehensive Biological Assessment And Photocatalytic Activity of Surfactant Assisted Solvothermal Synthesis of Zno Nanogranules, Mater. Chem. Phys., Vol. 215, Pp. 148-156, Aug. 2018.

7. I. Shahabi-Ghahfarrokhi And A. Babaei-Ghazvini. Using Photo-Modification To Compatibilize Nano-Zno In Development of Starch-Kefiran-Zno Green Nanocomposite As Food Packaging Material, Int. J. Biol. Macromol., Vol. 124, Pp. 922-930, Mar. 2019.

8. S. Alamdari, M. S. Ghamsari, And M. J. Tafreshi. Optimization of Gallium Concentration To Improve The Performance of Zno Nanopowders For Nanophotonic Applications, Ceram. Int., Oct. 2019.

9. P. S. Korrapati, K. Karthikeyan, A. Satish, V. R. Krishnaswamy, J. R. Venugopal, And S. Ramakrishna. Recent Advancements In Nanotechnological Strategies In Selection, Design And Delivery of Biomolecules For 
Skin Regeneration, Materials Science And Engineering C, Vol. 67. Elsevier Ltd, pp. 747-765, 01-Oct-2016.

10. N. Chandra Mohana, C. Mahendra, H. C. Yashavantha Rao, M. R. Abhilash, And S. Satish. Hydrothermal Combustion Based Zno Nanoparticles From Croton Bonplandianum: Characterization And Evaluation of Antibacterial And Antioxidant Potential, Sustain. Chem. Pharm., Vol. 14, Dec. 2019.

11. K. Nithya, and S. Kalyanasundharam. Effect of Chemically Synthesis Compared To Biosynthesized Zno Nanoparticles Using Aqueous Extract Of C. Halicacabum and Their Antibacterial Activity, Opennano, Vol. 4, Jan. 2019.

12. S. Ahmed, Annu, S. A. Chaudhry, And S. Ikram. A Review on Biogenic Synthesis of Zno Nanoparticles Using Plant Extracts and Microbes: A Prospect Towards Green Chemistry, Journal of Photochemistry And Photobiology B: Biology, Vol. 166. Elsevier B.V., pp. 272-284, 01-Jan-2017.

13. J. Singh, T. Dutta, K. H. Kim, M. Rawat, P. Samddar, And P. Kumar. Green Synthesis of Metals and Their Oxide Nanoparticles: Applications for Environmental Remediation, Journal of Nanobiotechnology, Vol. 16, No. 1. Biomed Central Ltd., 30-Oct-2018.

14. X. Lai, R. Guo, H. Xiao, J. Lan, S. Jiang, C. Cui, and E. Ren. Rapid Microwave-Assisted Bio-Synthesized Silver/Dandelion Catalyst With Superior Catalytic Performance for Dyes Degradation, J. Hazard. Mater., Vol. 371, No. March, Pp. 506-512, 2019.

15. A. Baghizadeh, S. Ranjbar, V.K. Gupta, M. Asif, S. Pourseyedi, M.J. Karimi, and R. Mohammadinejad. Green Synthesis of Silver Nanoparticles Using Seed Extract of Calendula Officinalis In Liquid Phase, $J$. Mol. Liq., Vol. 207, pp. 159-163, 2015.

16. L. Katata-Seru, T. Moremedi, O. S. Aremu, I. Bahadur. Green Synthesis of Iron Nanoparticles Using Moringa Oleifera Extracts And Their Applications: Removal of Nitrate From Water and Antibacterial Activity Against Escherichia Coli, J. Mol. Liq., Vol. 256, Pp. 296-304, 2018.

17. F. M. S.M.H. Akhter, Z. Mahmood, S. Ahmad. Plant-Mediated Green Synthesis of Zinc Oxide Nanoparticles Using Swertia Chirayita Leaf Extract, Characterization And Its Antibacterial Efficacy Against Some Common Pathogenic Bacteria, In J. Bionanosci., 8, pp. 811-817, 2018.

18. S. M. S.I. Hong, P. Ganeshan, A. Vincent. Green Synthesis and Characterization of Zinc Oxide Nanoparticle Antimicrobial Anticancer Activity Using Insulin Plant (Costus Pictus D. Don) Leaf Extract, In Advanced National Science Nanoscience Nanotechnology, 2018.

19. A. Kołodziejczak-Radzimska, and T. Jesionowski. Zinc oxide-from synthesis to application: a review, Materials, 7(4), pp.2833-2881.2014.
20. S. L. W. P. Raveendran, J. Fu. Completely 'Green' Synthesis and Stabilization of Metal Nanoparticles, In J. Am. Chemical. Society, 2003, P. 125.

21. S. Iravani, Green Synthesis of Metal Nanoparticles Using Plants, In Green Chemistry, pp. 2638-2650. 2011.

22. C. E. Farrugia, E. S. Burke, M. E. Haley, K. T. Bedi, And M. A. Gandhi, "Complementary Therapies In Clinical Practice The Use of Aloe Vera In Cancer Radiation: An Updated Comprehensive Review, Complement. Ther. Clin. Pract., Vol. 35, No. January, Pp. 126-130, 2019.

23. C. Peng, W. Zhang, C. Dai, W. Li, X. Shen, Y. Yuan, L. Yan, W. Zhang, and M. Yao. Study of The Aqueous Extract of Aloe Vera And Its Two Active Components on The Wnt / B -Catenin And Notch Signaling Pathways In Colorectal Cancer Cells, Journal of ethnopharmacology, 243, p.112092. May, 2019.

24. G. Canche-Escamilla, P. Colli-Acevedo, R. Borges-Argaez, P. Quintana-Owen, J.F. May-Crespo, M. Cáceres-Farfan, J.A.Y. Puc, P. Sansores-Peraza, and B.M. Vera-Ku. Extraction of Phenolic Components From an Aloe Vera ( Aloe Barbadensis Miller ) Crop and Their Potential As Antimicrobials And Textile Dyes, Sustainable Chemistry and Pharmacy, 14, p.100168.2019.

25. P.K. Sahu, D.D. Giri, R. Singh, P. Pandey, S. Gupta, A.K. Shrivastava, A. Kumar, and K.D. Pandey. Therapeutic and medicinal uses of Aloe vera: a review. Pharmacology \& Pharmacy, 4(08), p.599. 2013.

26. T. K. Mendy, A. Misran, T. M. M. Mahmud, And S. I. Ismail. Scientia Horticulturae Antifungal Properties of Aloe Vera Through In Vitro and In Vivo Screening Against Postharvest Pathogens of Papaya Fruit, Sci. Hortic. (Amsterdam)., Vol. 257, No. August, P. 108767, 2019.

27. V. Koutu, L. Shastri, And M. M. Malik. Effect of Naoh Concentration on Optical Properties of Zinc Oxide Nanoparticles, Mater. Sci. Pol., Vol. 34, No. 4, Pp. 819-827, Dec. 2016.

28. K.R. Beyerlein, J. Solla-Gullón, E. Herrero, E. Garnier, F. Pailloux, M. Leoni, P. Scardi, R.L. Snyder, A. Aldaz, and J.M. Feliu. Characterization of (111) Surface Tailored Pt Nanoparticles By Electrochemistry and X-Ray Powder Diffraction, Mater. Sci. Eng. A, Vol. 528, No. 1, Pp. 83-90, 2010.

29. K. Chukwuma, E. M. Bordy, And A. Coetzer, "Evolution of Porosity And Pore Geometry In The Permian Whitehill Formation of South Africa - A Fe-Sem Image Analysis Study," Mar. Pet. Geol., Vol. 91, No. January, Pp. 262-278, 2018.

30. M. Mukrimin, A. O. Conrad, A. Kovalchuk, R. Julkunen-Tiitto, P. Bonello, And F. O. Asiegbu, "Fourier-Transform Infrared (Ft-Ir) Spectroscopy Analysis Discriminates Asymptomatic and 
Symptomatic Norway Spruce Trees," Plant Sci., Vol. 289, No. September, P. 110247, 2019.

31. S. Kaiser, Â.R. Carvalho, V. Pittol, E.M. Peñaloza, P.E. de Resende, F.L.F. Soares, and G.G. Ortega. Chemical Differentiation Between Uncaria Tomentosa And Uncaria Guianensis By Lc-Pda, Ft-Ir and Uv Methods Coupled To Multivariate Analysis: A Reliable Tool For Adulteration Recognition, Microchem. J., Vol. 152, No. September 2019, p. 104346, 2020.

32. C. Chinnasamy, P. Tamilselvam, B. Karthick, B. Sidharth, and M. Senthilnathan. Green Synthesis, Characterization and Optimization Studies of Zinc Oxide Nano Particles Using Costusigneus Leaf Extract, Materials Today: Proceedings, 5(2), pp.6728-6735, 2018.

33. S. Shamaila, A.K.L. Sajjad, S.A. Farooqi, N. Jabeen, S. Majeed,and I. Farooq. Advancements in Nanoparticle Fabrication By Hazard Free Eco-Friendly Green Routes, Applied Materials Today, Vol. 5. Elsevier Ltd, Pp. 150-199, 01-Dec-2016.

34. T. Isık, M. E. Hilal, And N. Horzum. Green Synthesis Of Zinc Oxide Nanostructures, In Zinc Oxide Based Nano Materials and Devices. IntechOpen, 2019

35. Pubchem, "U.S. National Library Of Medicine National Center For Biotechnology Information." [Online]. Available:

Https://Pubchem.Ncbi.Nlm.Nih.Gov/Compound/ZincOxide. [Accessed: 19-Oct-2019].

36. P. Uikey and K. Vishwakarma. Review of Zinc Oxide ( Zno ) Nanoparticles Applications and 56 Properties, International Journal of Emerging Technology in Computer Science \& Electronics, 21(2), pp.239-42, 2016

37. D. Sengupta, P. Das, B. Mondal, And K. Mukherjee. Effects of Doping, Morphology and Fi Lm-Thickness of Photo-Anode Materials for Dye Sensitized Solar Cell Application - A Review, Renew. Sustain. Energy Rev., Vol. 60, Pp. 356-376, 2016.

38. G. Parthasarathy, M. Saroja, and M. Venkatachalam.

Bio-Synthesized Nano-Formulation Of Zinc Oxide-Aloe Vera and To Study Their Characterization And Antibacterial Activities Against Multiple Pathogens, Int. J. Pharm. Sci. Res., Vol. 8, No. 2, Pp. 900-907, 2017.

39. R. Majumder, C. K. Das, And M. Mandal. Lead Bioactive Compounds of Aloe Vera As Potential Anticancer Agent, Pharmacol. Res., Vol. 148, No. May, P. 104416, 2019.

40. E. Varghese And M. George. Green Synthesis of Zinc Oxide Nanoparticles, International Journal of Advance Research in Science and Engineering, 4(01).2015.
41. J.-Y. Kim, M. Kim, H. Kim, J. Joo, J.-H. Choi. Electrical and Optical Studies of Organic Light Emitting Devices Using Swcnts-Polymer Nanocomposites, Optical Materials, Volume 21, Issues 1-3, Pages 147-151, January 2003

42. B.A. Abbasi, J. Iqbal, R. Ahmad, L. Zia, S. Kanwal, T. Mahmood, C. Wang, and J.T. Chen. Bioactivities of Geranium Wallichianum Leaf Extracts Conjugated With Zinc Oxide Nanoparticles, Biomolecules, Vol. 10, No. 1, Pp. 1-19, 2020.

43. K. Ali, S. Dwivedi, A. Azam, Q. Saquib, M.S. Al-Said, A.A. Alkhedhairy, and J. Musarrat. Aloe Vera Extract Functionalized Zinc Oxide Nanoparticles As Nanoantibiotics Against Multi-Drug Resistant Clinical Bacterial Isolates," J. Colloid Interface Sci., Vol. 472, pp. 145-156, Jun. 2016.

44. A.A. Sokolovsky, A.I. Zemtsov, D.I. Kovalev, E.M. Shishkov, and A.A. Kazantsev. Hybrid Fiber Optic Temperature Sensor Powered by Optical Radiation, International Journal of Emerging Trends in Engineering Research, 7, No.12, p.854-856, 2019.

45. B. Abbas, and A. Hashim. Novel X-rays attenuation by (PMMA-PS-WC) New Nanocompsites: Fabrication, Structural, Optical Characterizations and X-Ray Sheilding Application, International Journal of Emerging Trends in Engineering Research, 7, No.8, p.131-144, 2019. 